“드 2013 IEEE. Personal use of this material is permitted. Permission from IEEE must be obtained for all other uses, in any current or future media, including reprinting/republishing this material for advertising or promotional purposes, creating new collective works, for resale or redistribution to servers or lists, or reuse of any copyrighted component of this work in other works." 


\section{Brushless Permanent Magnet DC and AC Motor and Synchonous Reluctance Motor Design for Racing Motorcycles}

\author{
David G. Dorrell \\ School of Electrical, Mechanical and Mechatronics Systems \\ University of Technology Sydney \\ Sydney, Australia \\ David.dorrell@uts.edu.au
}

\author{
Mircea Popescu \\ Motor Design Ltd. \\ Elsmere, Shropshire, SY12 0EG, UK \\ Mircea.popescu@motor-design.com
}

\begin{abstract}
There is an increasing interest in electric transportation. Most large manufacturers now produce hybrid versions of their popular models and in some countries electric cycles and scooter are now popular. Motor sport is often used to develop technology and in this paper designs for electric racing motorcycles are addressed. These are in-frame motors (rather than hub motors which can affect handling and are not as powerful). Typically 10 to $12 \mathrm{~kW}$-hours of batteries can be carried on the cycle and the batteries are almost exhausted at the end of a race. Therefore very high efficiency over a range of operation is needed, but also the motors need to be compact and have high torque density. This paper examines the use of permanent magnet motors and possible designs.
\end{abstract}

Keywords- Brushless permanent magnet motors, rare earth magnet, motorcycles.

\section{INTRODUCTION}

The use of brushless permanent magnet DC drive motors in racing motorcycles is discussed in this paper. The load application requirements are highlighted in Fig 1. Practical converters for this type of application [1] are usually quite simple and work in the constant torque region and at low voltage so the motor needs to be carefully matched. The motor cycles themselves have a limited battery capacity [2] so a high efficiency motor is required. Because high torque is also required and low voltage is used then there is a trade-off between the voltage and torque constants. The load requirements for the machine are crucial and this briefly illustrated in Fig. 1 but it should be born in mind that duty cycling is necessary so that high current can be used under hard acceleration. Gearing is important in this application. Road wheels will typically run at $1500 \mathrm{rpm}$ at $200 \mathrm{~km} /$ hour which is a little low; [3] addresses a machine that incorporates a motor into a magnetic gear and expressly states that this could be used in a motorcycle. Several papers further address scooter drive motor design (examples being [4]-[6]) and many, such as [7], investigate the control of scooter drives. However there is little on more powerful motorcycle drives and recently racing motorcycles have moved from DC to AC and are very power dense [8].

\section{REVIEW OF LITERATURE}

In terms of electromagnetic design of automotive machines then wide speed range is required such as those designed in [9] and [10]. When designing the drive motors, simple design is required. This is shown in [11]. Algorithms can be applied to help in the design [12]. Drive motors for automotive applications often operate up to $25 \mathrm{~A} / \mathrm{mm}^{2}$ and are liquid cooled. Duty cycling is used to prevent overheating. However, in a racing environment the duty cycle is expected to by high.

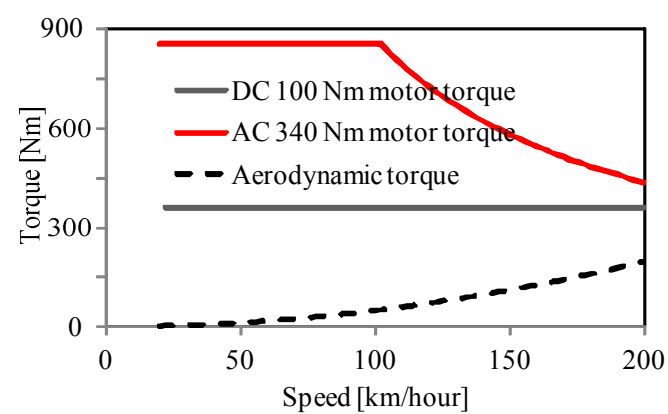

Fig. 1. DC and AC drive torque/speed characteristics.

A possible topology was outlined in [13] which used an 18 stator slot and 6 pole rotor with one slot pitch for the winding; simulations were carried out at the maximum load point of $6000 \mathrm{rpm}(200 \mathrm{~km} /$ hour$)$ and about $100 \mathrm{Nm}$ (the paper gives more details on the load requirement than can be discussed here). In [14] this was taken further and a 9-slot 6-pole arrangement with interior rare earth magnets (IPMs) was designed. A size reduction exercise was conducted and AC control was assessed. This gives improved performance. [13] and [14] give details of the drive and load requirement and space restrictions prevent further detailed discussion here. However, Fig. 1 highlights the torque for a DC drive suitable for a controller such as in [1] and an improved $\mathrm{AC}$ drive that appears to have been used in [8]. The lower constant-torque characteristic is for a more straightforward control that can give $100 \mathrm{Nm}$ of torque which is increased by gearing to $360 \mathrm{Nm}$ of torque at the road wheel up to $200 \mathrm{~km} / \mathrm{h}$.

For a typical racing cycle, the weight of the cycle and rider is taken as $275 \mathrm{Kg}$. The Motoczysz machine used in the TT 
race [15] reaches this speed much sooner than a constanttorque machine generating $100 \mathrm{Nm}$ and then the speed is constant. At $100 \mathrm{mph}(160 \mathrm{~km} / \mathrm{h})$ the power being used to overcome the aerodynamic losses is about $17.3 \mathrm{~kW}$. Therefore, with $10 \mathrm{~kW}$-hours of stored energy there is a possible 34.5 minutes of constant operation. This illustrates that there is a restriction in both the top speed and time of a race.

In this paper the designs will be more closely investigated and some thermal design detailed. These high performance machines pose more of a thermal problem than an electromagnetic problem. The designs here use a substantial amount of rare earth magnet material. The last part of the paper briefly addresses the issue of magnet reduction by use of a synchronous reluctance rotor. The work in [16] reduces the magnet to a minimum but here we will study the complete removal of the permanent magnets. The drive motors in the Toyota Prius have been shown to have substantial amount of reluctance torque [17].

\section{ROTOR TOPOLOGY FOR DC MACHINE AND THERMAL ASSESSMENT}

Some basic parameters of a reduced size motor that is DC driven was reported in [14]. The topology and performance predictions are put forward in Table I, and in Figs. 2 and 3. These are obtained from design software SPEED PC-BDC and PC-FEA (for magnetics) and Motor-CAD (for thermal). These are common industrial packages. When unskewed, there is a substantial amount of cogging but this can be reduced with skew; as illustrated. IPMs are used to reduce magnet loss as well as allow reluctance torque. It may be thought that torque ripple is not important here because an internal combustion engine does have considerable torque ripple. However, this is not quite correct since the internal combustion engine may have a large flywheel and also it is inherent, whereas it can be removed in an electric motor and this leads to less tire wear and better motorcycle handling.

TABLE I. MOTOR PARAMETERS AND PERFORMANCE

\begin{tabular}{|c|c|c|c|}
\hline Slots & 9 & Magnet weight [Kg] & 2.00 \\
\hline Poles & 8 & Copper weight $[\mathrm{Kg}]$ & 4.57 \\
\hline Magnet $\mathrm{Br}[\mathrm{T}]$ & 1.12 & Total weight $[\mathrm{Kg}]$ & 22.33 \\
\hline Outer diameter [mm] & 240 & Axial core length [mm] & 85 \\
\hline Copper loss [W] & 915 & Iron loss [W] & 141 \\
\hline \multicolumn{2}{|c|}{ Performance (Unskewed) } & \multicolumn{2}{|c|}{ Performance (Skewed one slot) } \\
\hline Torque $[\mathrm{N}]$ & 85.3 & Torque $[\mathrm{N}]$ & 84.6 \\
\hline Peak-to-peak ripple [\%] & 34.2 & Peak-to-peak ripple [\%] & 4.3 \\
\hline Efficiency [\%] & 98.1 & Efficiency [\%] & 97.3 \\
\hline
\end{tabular}

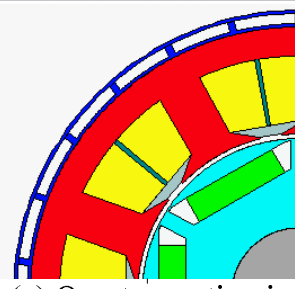

(a) Quarter section in motor-Cad

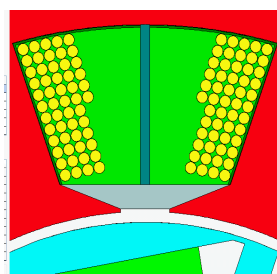

(b) slot and turns in (c) Single slot pitch; showing low slot fill diametric asymmetry
Fig. 2. Motor topology showing low slot fill and one slot pitch coils.

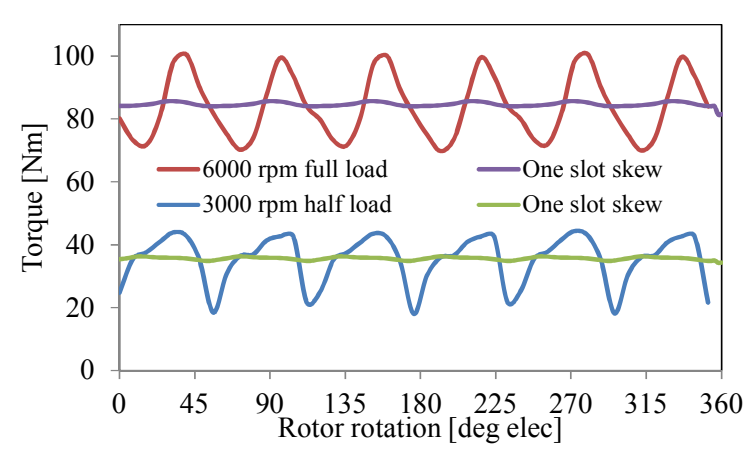

Fig. 3. Torque at half load and full load with and without skew.

Cooling is vital for these machines and for this machine a duty cycle was set up to test the thermal performance. This is shown in Fig. 4. Thermal performance is very much a function of the cooling system, the winding potting, and the thermal conduction at material boundaries. However, typical methods and values are used in the thermal assessment of this motor.

For the control simulation of the machine, static finite element analysis was used to obtain the torque; however, the current was calculated with a dynamic simulation so it was not a simple trapezoidal waveform as shown in Fig. 5. In [17] it was illustrated that phase advance can be used to increase in torque. However in a DC machine with fractional slot topology it is difficult to use the rotor saliency. This is illustrated in Fig. 6 - the torque is maximum almost on the q-axis for a set current (maximum torque).

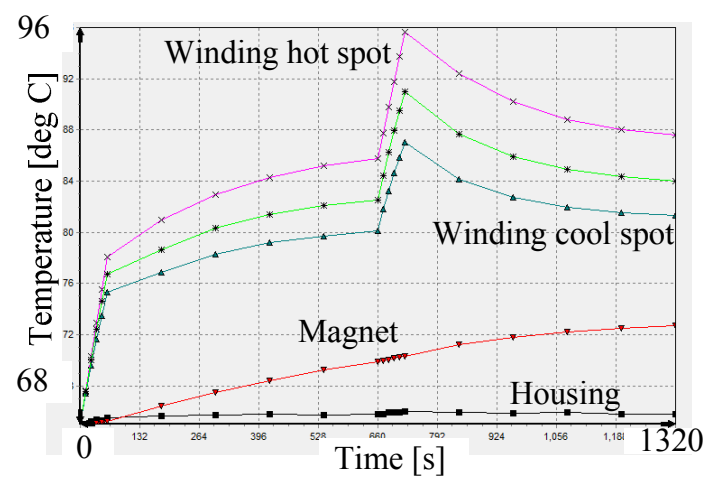

Fig. 4. Winding steady-state temperature variation with $20 \mathrm{~L} / \mathrm{min}$ flow and duty cycling wiht $800 \mathrm{~A}$ for one minute for 10 minutes and two successive cycles.
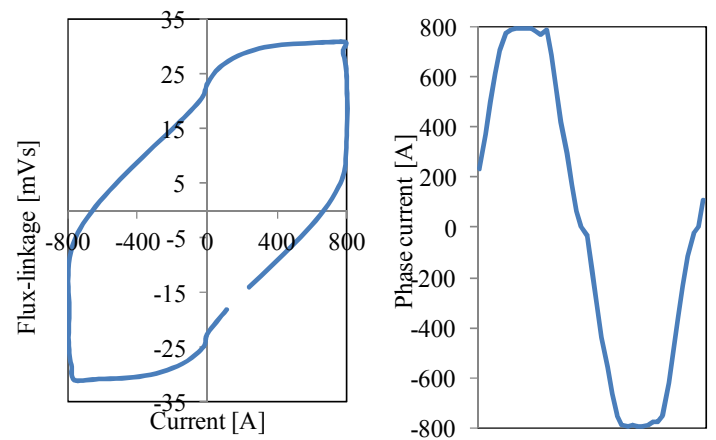

Fig. 5. Current - flux-linkage loop and current at full load showing simulation current of DC control from PC-BDC dynamic simulation. 


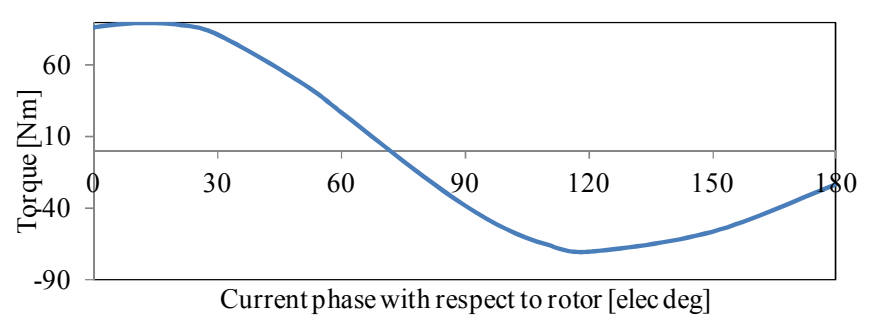

Fig. 6. Variation of torque with current phase angle with respect to the $\mathrm{q}$ axis.

\section{Rotor TOPOlOgiES FOR A High PERFormanCE AC MACHINE}

\section{A. Spoke Rotor}

In [14] a spoke rotor machine with fractional slots was designed to match the high torque requirement. This is again a fractional slot machine with 12 slots and 8 poles. The coil pitch is one slot to make the winding neat. The spoke arrangement is shown in Fig. 7. The properties of the machine are given in Table II. This is aimed at producing over $300 \mathrm{Nm}$ as a high torque machine. The thermal analysis was put forward in [14]. Here we will address the variation of current with $q$ axis. Fig. 8 shows the current - flux-linkage loops (which is the most accurate way to calculate the torque in a highly saturated machines) and this seems to illustrate good energy conversion. In Fig. 9 the current at maximum torque is maintained but varied with respect to the $\mathrm{q}$ axis. It can be seen that there is a small increase in torque at a 20 deg elec phase advance. In [17] an IPM showed significant torque boosting with phase advance so in the next sections different rotor topologies are investigated.
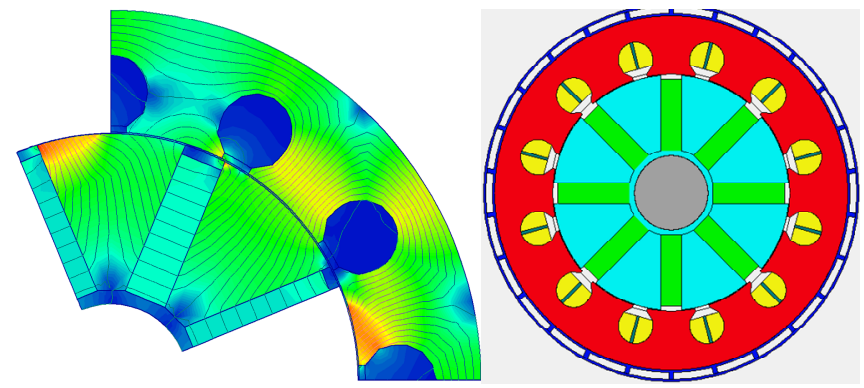

Fig. 7. Fig. 7. High torque spoke AC motor.

TABLE II. DESIGN AND PERFORMANCE PARAMETERS FOR AC CONTROLLED MACHINE DESIGN - FULL LOAD POINT TAKEN AT 2118 RPM AND 424 A RMS NOMINAL FOR LINE CURRENT (339 A DC LINK); DYNAMIC SIMULATION INCLUDING SWITCHING.

\begin{tabular}{|c|c|}
\hline Outer diameter [mm] & 240 \\
\hline Axial core length [mm] & 120 \\
\hline Rotor diameter [mm] & 160 \\
\hline Magnet Br [T] & 1.12 \\
\hline Magnet weight [Kg] & 4.76 \\
\hline Copper weight [Kg] & 2.36 \\
\hline Total weight [Kg] & 35.17 \\
\hline Torque [N] & 330.0 \\
\hline Copper loss [W] & 3315 \\
\hline Iron loss [W] & 436 \\
\hline Efficiency [\%] & 95.1 \\
\hline
\end{tabular}
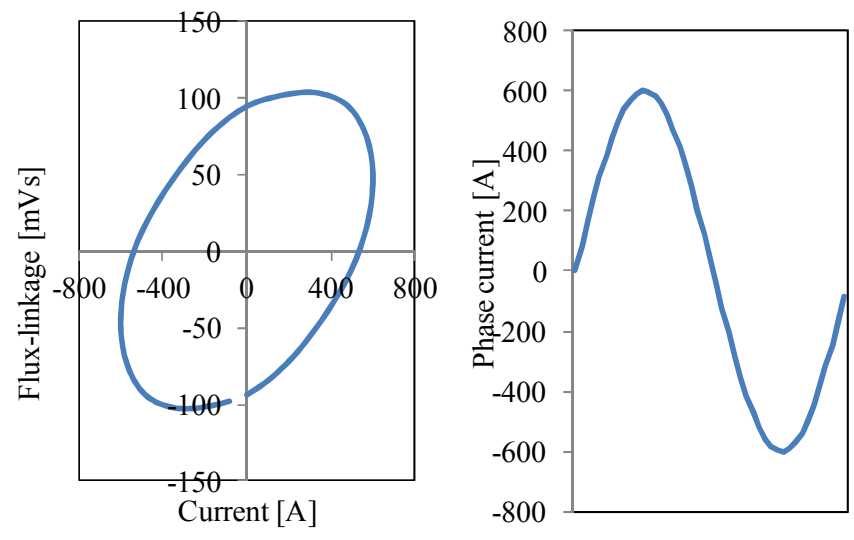

Fig. 8. High torque spoke AC motor: current - flux-linkage loop with current on q-axis; sine wave current used (time on $\mathrm{x}$ axis on right).

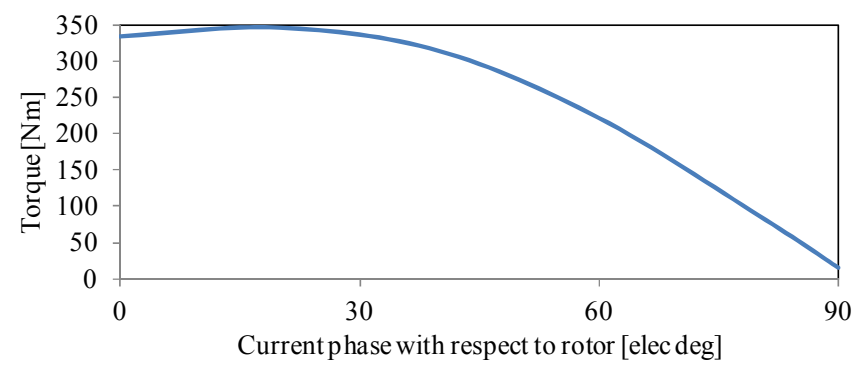

Fig. 9. High torque spoke AC motor - With set current angle with respect to q-axis is varied.

\section{B. IPM Rotor Design}

To investigate the use of an IPM rotor with this stator design then the rotor was changed for the design shown in Fig. 10. This contains the same amount of magnet material as the spoke motor used in the previous section. Again, the same simulation was carried out with the same current that produced maximum torque and the results of the simulation are given in Fig. 11. As with all the simulations in this paper, current fluxlinkage loops are used to calculate the torque. It can be seen that the torque is less than the spoke design (by about $30 \%$ ). There is some more q-axis saliency but it is not as pronounced in the design for the Toyota Prius design in [17]. It can be concluded that very careful design is required to maximize the effects of q-axis saliency.
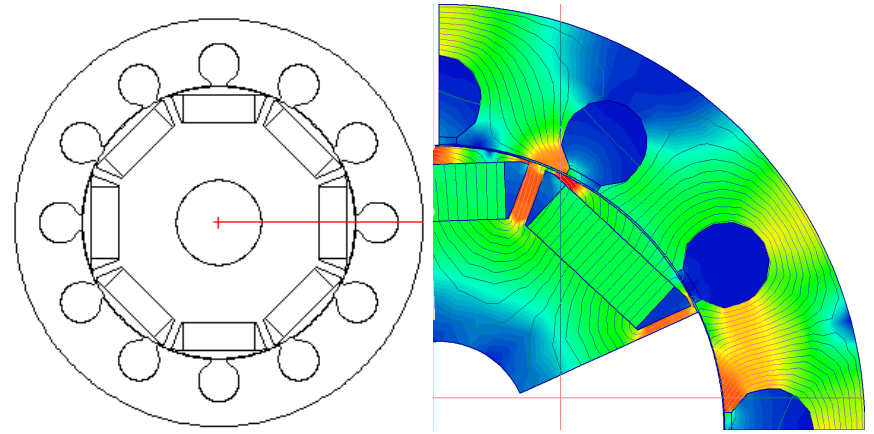

Fig. 10. High torque AC motor with IPM rotor. 


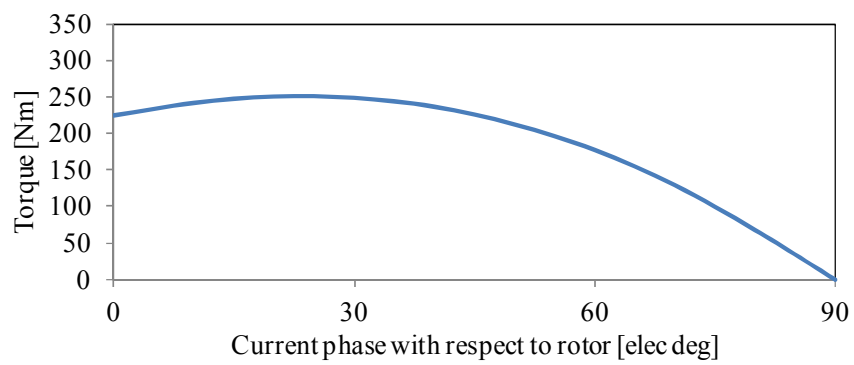

Fig. 11. High torque spoke AC motor with IPM rotor - torque from current flux-linkage loops and sine wave current used as in Fig. 8.

\section{Multi-Layer IPM Rotor}

It is possible to use multilayer IPM rotors. These can have substantial torque and saliency effects. The rotor was changed to a six layer per pole set of magnets as shown in Fig. 12 with the same stator and same amount of magnet material in the rotor. There are twelve magnets pole.
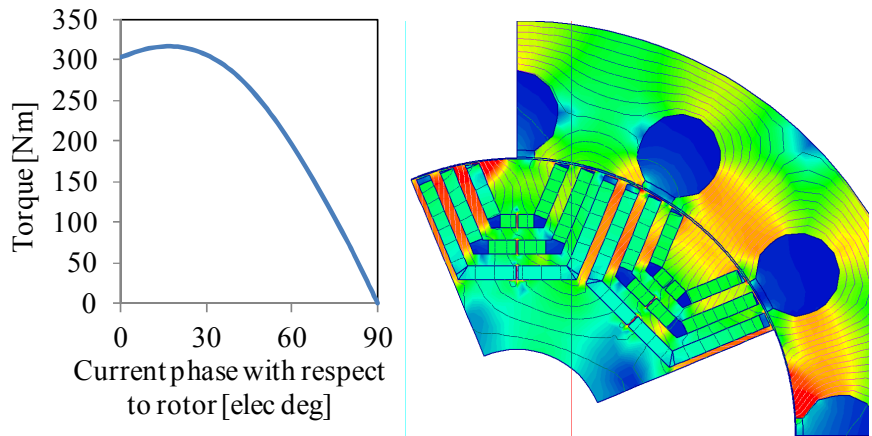

Fig. 12. Fig. 12. High torque AC motor with multilayer IPM rotor - torque from current - torque from flux-linkage loops and sine wave current used as in Fig. 8.

It can be seen that the multilayer rotor does have some saliency but it is still dominated by the excitation torque. The torque profile is very similar to the spoke rotor but would be somewhat more difficult to construct. However, the use of smaller magnets may be advantageous. For a particular stator design and loading, the torque is strongly influenced by the amount of magnet in the rotor, and a variety of rotor topologies can be used to realize this torque.

\section{4-Pole Alternative}

A 4-pole design can be tested against the 8-pole design. The same stator was kept but this time the coils are fully pitched and arranged into a 4-pole winding so that there would be increased copper losses. The magnet material is maintained. Using the same current loading again, the torque was found to be reduced from the 8-pole spoke motor. Fig. 13 shows a flux distribution when loaded and the current is on the $q$ axis. It can be seen that this is not a correct design. The yoke and stator teeth are heavily saturated. In order to maintain the same envelope then the rotor diameter has to be reduced to accommodate for increased stator yoke thickness. This is done as shown in Fig. 14. The slots are also adjusted so that the slot area is the same. The rotor diameter is reduced from 160 to 140 $\mathrm{mm}$. Since the rotor is smaller, then the amount of magnet material is now reduced from about $4.75 \mathrm{Kg}$ to $4.1 \mathrm{Kg}$. A comparison of the two 4-pole machine performances is shown in Fig. 15. The reduced rotor diameter machine gives better performance. The performance is still below the 8-pole machine performance although the iron loss needs to be carefully assessed because the flux frequency is half that of the 8 pole machine at a given speed.

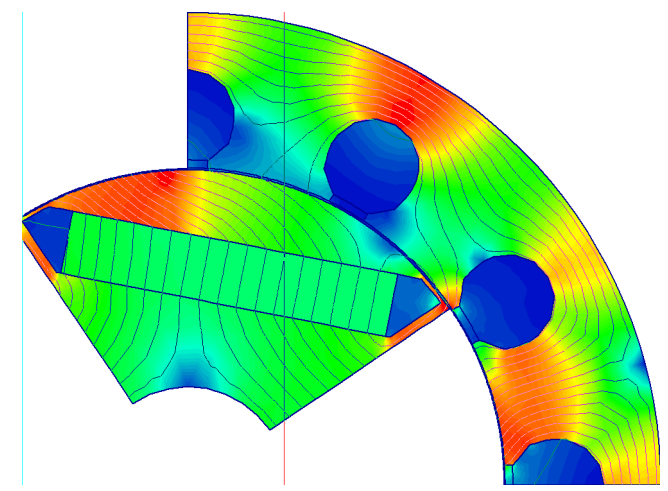

Fig. 13. High torque AC motor with 4 poles and an IPM rotor.

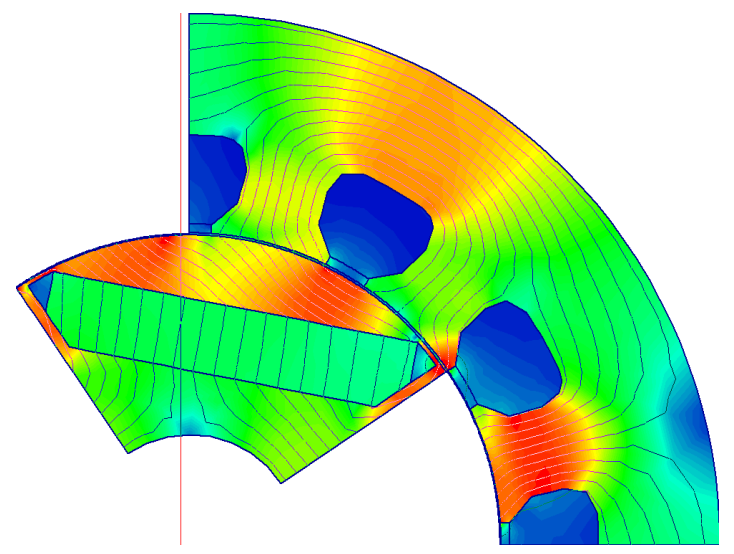

Fig. 14. High torque AC motor with 4 poles and a IPM rotor - rotor diameter is reduced from 160 to $140 \mathrm{~mm}$.

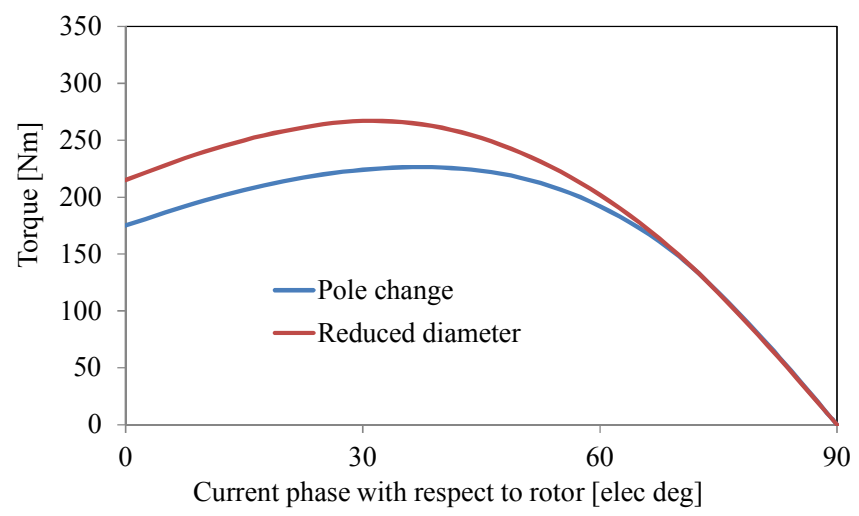

Fig. 15. Comparison of the torque for the 4-pole designs under idential loading conditions - torque from current - flux-linkage loops and sine wave current used as in Fig. 8. 
VI. SYNCHRONOUS RELUCTANCE ALTERNATIVE

There is much interest in magnetless machines. The multilayer rotor is very similar to that in a synchronous reluctance machine. In order to investigate the performance of the rotor topology in Fig. 12 in terms of a synchronous reluctance machine then the magnets were switched off and the simulation repeated.
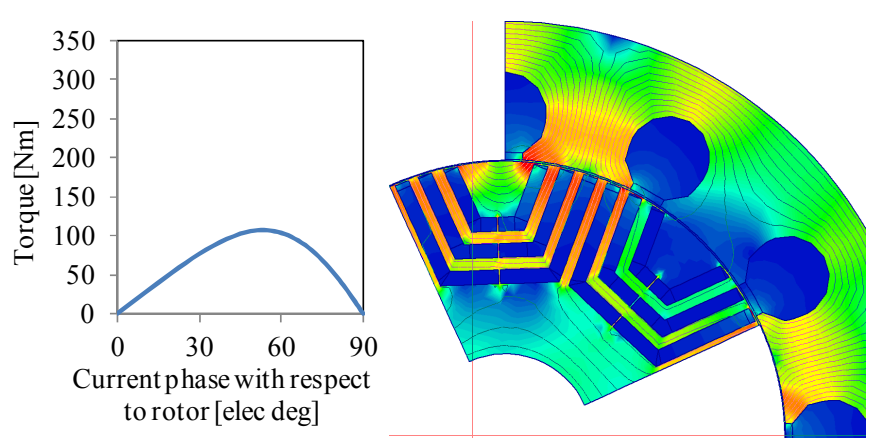

Fig. 16. High torque AC motor with synchronous reluctance rotor - torque from current - flux-linkage loops and sine wave current used as in Fig. 8.

The results are shown in Fig. 16. It can be seen that the torque in now a reluctance torque and the characteristic is much reduced - the peak torque is only a third compared to the simulations with magnets. The reduction in torque is such that redesign is unlikely to realize a machine with torque even approaching that of the IPM machine. Fractional slot windings appear not to be very effective in these machines. Further current is required to provide the machine excitation in some way.

\section{CONCLUSION}

This paper simply outlines the design for a racing motorcycle drive motor. A spoke rotor permanent magnet design that has already been assessed is further investigated and a variety of alternative arrangements tested. The same stator and loading is used for comparison and is found that the spoke motor produces the best results. However, this should not be generalized; the torque variation compared to the IPM machine suggests that further design could improve the IPM performance and that the torque is closely related to the amount of permanent magnet material used rather than the rotor design since the multi-layered design gave good results too. A synchronous reluctance rotor gives much poorer performance in comparison.

\section{REFERENCES}

[1] http://kellycontroller.com/khb1480124-144v800aopto-bldccontrollerwith-regen-p-822.html

[2] TTXGP, Technical Rules, 2012 Season, http://www.egrandprix.com.

[3] K. T. Chau, Dong Zhang, J. Z. Jiang, Chunhua Liu and Yuejin Zhang, "Design of a Magnetic-Geared Outer-Rotor Permanent-Magnet Brushless Motor for Electric Vehicles," IEEE Trans. on Magn. Vol 43, No. 4, 2007, pp 2504-2506.

[4] P. Minciunescu, R. Balaban, C. Minciunescu and M. Chefneux "Permanent Magnet Brushless Machine for a Hybrid Electric Scooter." 7th Int. Symp. Advanced Topics in Electrical Engineering, Bucharest, May 2011, pp 1-4.

[5] Byeong-Mun Song; Jang-Young Choi, "A low-speed high-torque permanent magnet motor for electric scooters," IEEE Vehicle Power and Propulsion Conf., Sept 2011 pp 1-6.

[6] Byeong-Mun Song; Ki-Chan Chang; Jang-Young Choi, "Design of an outer-rotor-type permanent magnet motor for electric scooter propulsion systems," Int. Power Electronics Conf., June 2010, pp 2736-2742.

[7] D. Fodorean and L. Szabo, "Control of a permanent magnet synchronous motor for electric scooter application," Int. Symp. on Power Electronics, Electrical Drives, Automation and Motion, June 2012, pp 1178-1181.

[8] http://www.motorcyclenews.com/MCN/News/newsresults/Generalnews/ 2010/Februaryfeb2710-motoczysz-launches-plugnplay-powertrain/

[9] F. Parasiliti, M. Villani, S. Lucidi, and F. Rinaldi, "Finite-ElementBased Multiobjective Design Optimization Procedure of Interior Permanent Magnet Synchronous Motors for Wide Constant-Power Region Operation," IEEE Trans. on Industrial Electronics, Vol. 59, No. 6, June 2012, pp 2504-2514.

[10] Hyung-Woo Lee, Ki-Doek Lee, Won-Ho Kim, Ik-Sang Jang, Mi-Jung Kim, Jae-Jun Lee, and Ju Lee, "Parameter Design of IPMSM With Concentrated Winding Considering Partial Saturation," IEEE Trans. on Magn. Vol. 47, No. 10, 2011, pp 3653-2656.

[11] D. G. Dorrell, M.-F. Hsieh, M. Popescu, L. Evans, D. A Staton, and V. Grout, "A Review of the Design Issues and Techniques for Radial-Flux Brushless Surface and Internal Rare-Earth Permanent Magnet Motors", IEEE Trans. on Industrial Electronics, 2012.

[12] D. Fodorean, L. Idoumghar and L. Szabó, " Motorization for electric scooter by using permanent magnet machines optimized based on hybrid metaheuristic algorithm," IEEE Trans. on Vehicular Technology, 2012, IEEE Early Release.

[13] D. G. Dorrell, "Design of Brushless Permanent-Magnet DC Motors for Racing Motorcycles", IEEE ISIE Conf., Hengzhou, China, May 2012.

[14] D. G. Dorrell and M. Popescu, "Drive Motor Design for Electric Motorcycles", IEEE Energy Conversion Conference and Exposition (ECCE), Sept. 2012, pp 1-8.

[15] http://motoczysz.com/motorcycles/e1 pc_2010

[16] P. Guglielmi, M. Pastorelli, G. Pellegrino and A. Vagati, " PositionSensorless Control of Permanent-Magnet-Assisted Synchronous Reluctance Motor," IEEE Trans. on Ind. Appl., Vol. 40, No. 2, 2004, pp 615-622.

[17] D. G. Dorrell, M.-F. Hsieh and A. M. Knight, "Alternative Rotor Designs for High Performance Brushless Permanent Magnet Machines for Hybrid Electric Vehicles," IEEE Trans. on Magn., vol. 48, no. 2, 2012, pp $835-838$. 